\title{
E-Learning Diurnal Time Patterns in the Navy
}

\author{
Ruti Gafni \\ The Open University of Israel \\ Raanana, Israel \\ rutiga@openu.ac.il
}

\author{
Levi Shaul and Doron Tauber \\ Bar Ilan University, \\ Ramat Gan, Israel
}

\author{
levi.shaul@live.biu.ac.il; \\ doron.tauber@gmail.com
}

\begin{abstract}
E-learning provides the feasibility to learn in any time and any place, enlarging the possibilities to combine the routine duties with the learning ones. This research examines the diurnal time patterns of e-learning trainees in the Israeli Navy using the "Bareket" system, in distance learning courses and on-campus hybrid courses, according to populations, classes, levels and roles, based on the number of log-ins to the system at each hour of the day. The findings show that, although the fundamental usage of e-learning is performed during the working hours, the "diurnal" hours expand along the years, extending the time allotted for learning, especially in distance learning.
\end{abstract}

Keywords: e-learning, distance learning, hybrid learning, time management, time pattern.

\section{Introduction}

Online learning can remove the barriers of time and place; therefore it is suitable to provide learning and training in environments where the possibilities of gathering a course audience might be problematic or costly. E-learning systems are widespread implemented in high schools (Cukušić, Alfirević, Granić, \& Garača, 2010), universities (Naveh, Tubin, Pliskin, 2004; Trinidad \& Pearson, 2004; Vanijja \& Supattatham, 2006), medical organizations (Emami, Aqdasi, \& Asousheh 2008), business organizations (Hogarth \& Dawson, 2008; McPherson \& Nunes, 2006) and even in the army of various countries (Bonk \& Wisher, 2000; Juhary, 2005; Newton \& Ellis, 2005; Selim, 2007; Tung, Huang, Keh, \& Wai, 2009; Wisher \& Sabol, 2002). Such systems are used for knowledge management and training, enabling the maintenance and improvement of professional skills and competence (Allen, Mabry, Mattrey, Bourhis, Titsworth, \& Burrell, 2004; Elgort, 2005; Sela \& Sivan, 2009; Stonebraker \& Hazeltine, 2004; Wang, Wang, \& Shee, 2007; Zhang, Zhao, Zhou, \& Nunamaker, 2004;).

The benefits of an e-learning system are various and significant, such as knowledge conservation, standardization, availability and enhancement of course materials, flexibility according to the students capacity and needs and resources reduction (Kathawala \& Wilgen, 2004; Marengo \& Ma-

Material published as part of this publication, either on-line or in print, is copyrighted by the Informing Science Institute. Permission to make digital or paper copy of part or all of these works for personal or classroom use is granted without fee provided that the copies are not made or distributed for profit or commercial advantage AND that copies 1) bear this notice in full and 2) give the full citation on the first page. It is permissible to abstract these works so long as credit is given. To copy in all other cases or to republish or to post on a server or to redistribute to lists requires specific permission and payment of a fee. Contact Publisher@,InformingScience.org to request redistribution permission. rengo, 2005; Quentin-Baxter, Kelly, Probert, MacMahon, \& Merrell, 2008). One of the major benefits of e-learning, especially from the student's point of view, is the possibility to learn at any time and almost every place. A participant can access the learning program at any convenient time (24/7) not just during the specific period that is set for a conventional course. A second major 
benefit is the feasibility of distance learning, meaning that the participants do not have to meet in person. Students and teachers can be anywhere. Individuals can log on at work, home, the library, in a community learning center or from their hotel when traveling (Capper, 2003).

Studies of human activity patterns demonstrate that human behaviour in western cultural environments follows a time management pattern, which can be divided into two time resolutions: (1) Day of week patterns, organizing the week in work days and work free weekends; and (2) Diurnal patterns, organizing the day-to day activities base on the diurnal patterns of sleep, work and play (Klepeis et al., 2001). In this work the focus is on diurnal patterns.

The term "time management" is widely used for many types of activities. One of the contexts of this term is "personal time management" referring to the set of habits, rules and recommendations on how to manage one's personal time effectively and do as much work as possible within the given amount of time. Although the personal time management plays a key role in the educational process efficiency, there are also some other meanings of this term, referring mostly to the course time management and possibilities of an e-learning system (Foltynek \& Motycka, 2009). Another important determinant of time management success is the performance curve property and therefore each participant of the educational process needs to have the opportunity to take advantage of his/her own effective hours and take part of learning just in the optimum time which is guaranteed by the e-learning system itself, because it can be used 24 hours per day and 7 days a week, so anybody can use them whenever they want.

The time management is even more restricted and problematic when the students are recruited to the army, in which the time schedules are tight and not flexible. Tung et al. (2009) refer to the scarcity of time of the line officers in the Taiwan military, due to their work responsibilities, which cause that they rarely have time to leave their posts to take courses in a traditional college campus.

Several studies have been performed to find the usage time pattern of students learning online courses in universities and postgraduate studies (Lukaitis \& Davey, 2010; McVeigh, 2009; Spennemann, 2007; Spennemann, Atkinson, \& Cornforth, 2007; Vryonides, 2008). This paper analyzes the time learning patterns of trainees in the Israeli Navy, using the "Bareket", an e-learning system, according to course level and place.

Eight years ago, the Israeli Navy decided to implement the "Bareket" system, a training management system harnessing online learning, knowledge management and performance support concepts under one roof. "Bareket" system is a web-based learning content management system (LCMS) that has been designed for higher education and professional development needs. The "Bareket" system is designed to assist institutions in effectively managing all aspects of their campus-wide e-learning. The "Bareket" system enables the establishment of a virtual campus where learning, teaching and management can be done from anywhere, classrooms, offices or vessels, using a simple web based user interface. Using the "Bareket" system, the institution can, on one hand, manage a complex and dynamic set of content resources, share knowledge, access permissions, set up and maintain a central learning hub that helps instructors create rapidly online courses with complete flexibility and control. On the other hand, trainees can access online courses and curricula, collaborate with fellow trainees and instructors and take online exams and exercises, without the need to leave their office or vessel. Courses can be instructor-led, selfpaced or an addition to a traditional course. All training materials such as lesson plans, presentations, graphics, videos, doctrinal literature etc. are stored in the "Bareket" system. Powerful content archiving and retrieval features support complete digitization and standardization of training materials. Moreover, commanders and instructors can receive clear, detailed and customized situational reports covering different aspects of the course underway and on each one of the trainees. These advanced reporting and analyze capabilities allow commanders and instructors to identify, 
in real time, trends, gaps and various problems in the conduct of the course. In addition, trainees can be reached at their units before formal courses begin or after, mainly for completion of course prerequisites or advanced training at their units. Thus, the "Bareket" system enables low operational costs while enabling the broadest possible trainees' participation.

Today, the solution is in full production, highly appraised by command, with hundreds of concurrent users over the different hours of the day, online courses, communities and learning environments. The "Bareket" system includes hundreds of online courses for individual distance learning covering subjects such as sailing, safety, introduction to new vessels, hydrodynamic, marine architecture, meteorology, mechanics, electronics etc. Some of these courses are mandatory, such as the ones that qualify naval officers, staff or technicians on vessels or assimilate doctrinal subjects. The courses include online tutorials, tasks, announcements, examinations, multimedia, simulations and presentations, frequently asked questions (FAQs), documentation libraries etc. Today, the "Bareket" system is the sole infrastructure for training management systems for the Israeli Navy.

This research examines the changes in learning time pattern over the years, according to the evolvement of the implementation of the "Bareket" e-learning system, during its eight first years, from its initiation in 2004, during its establishment till 2007, and along its full activation till nowadays, at the end of 2010. Does the learning time pattern remain still during the years, or maybe the broadening of the implementation of the e-learning system and the realization of its benefits lead to an increase of learning hours? The learning time pattern is also examined according to various parameters, such as level of the courses, distance learning versus hybrid courses, etc., in order to inspect the differences in time management. This research tries to find whether these parameters influence on the learning time pattern.

\section{Methodology}

Data of the usage of the "Bareket" e-learning system in the Israeli Navy was collected during eight years. The "Bareket" system itself includes all data needed to perform the actual training, but does not contain history. In order to accumulate history data to inspect the evolution of the elearning system for this research, the relevant data was transferred regularly to a repository database. This history database includes daily data from eight years, from the beginning of the "Bareket" system usage in 2004 till 2010. This data can be divided into two different periods: first, from 2004 to 2006 in which the e-learning infrastructure was established, different courses and learning objects were developed but yet, only part of the courses were offered by the system. The second period analyzed, from 2007 to 2010 , when the system worked in its full capacity.

The data was accumulated and analyzed in a resolution of years to find the differences and tendencies change between those years. Moreover, one year, 2009, was fully analyzed. The reason of choosing this year is that it is the last complete year (January-December) and the "Bareket" system was fully adopted.

The "Bareket" e-learning system is used in two different ways:

(1) Distance learning - This method is used to make the courses feasible to trainees who cannot leave their duties to join a regular course. These are full e-learning courses, where the trainees learn at their own pace, without leaving their base or vessel, and combine working with studying, at their convenient hours. It may be clarified, that the use of the e-learning system in a vessel is different while sailing or harboring. During sail the "Bareket" can be used off-line. While harboring, the "Bareket" is in its full synchronized online use.

(2) Hybrid learning - This method is used in courses where the learning must be "on campus", combined with frontal lectures or practical training. In this case the trainees leave their bases 
and vessels and are gathered for a course defined time. During the course period, the "Bareket" system is available to the trainees, with the needed resources for the course. These trainees can use the e-learning system at any time of the day.

Figure 1 shows an ERD diagram of the data. The trainee belongs to a department, which defines the learning type (Distance or Hybrid), the class and the level. At any given time, each trainee studies in one course, which can be populated by any number of trainees. Each trainee can perform any number of log-ins to the system.

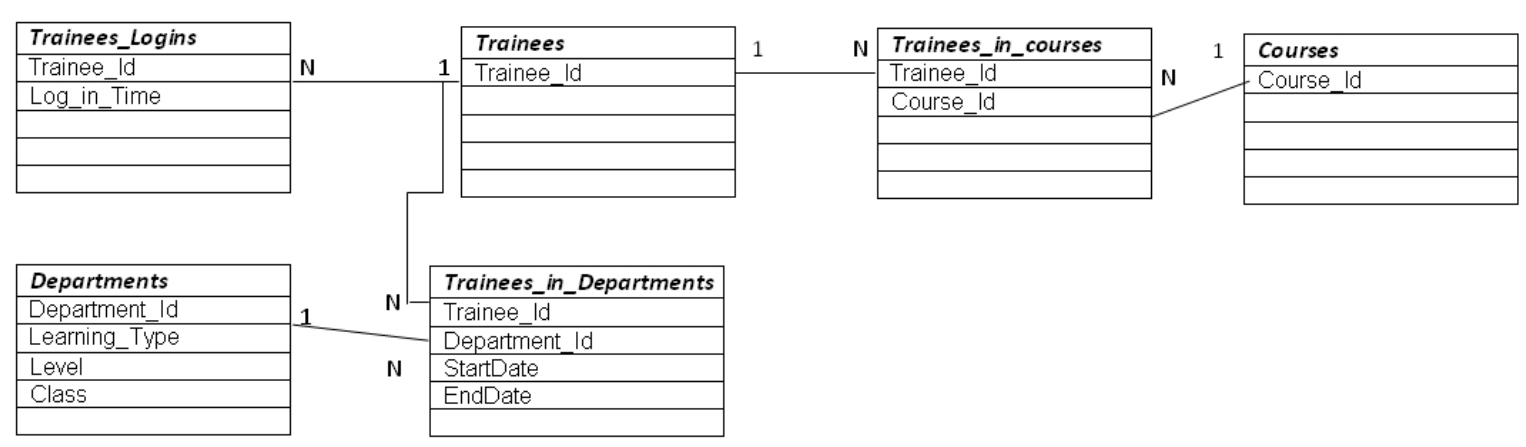

Figure 1 - ERD of the Data Accumulated

For this research, the data accumulated consisted on the log-ins of the trainees to the "Bareket" system, i.e., when and how many times did trainees entered the system. The data was accumulated and analyzed according to the hour of log-in.

The time patterns were examined and compared, according to the following parameters:

- Tendencies of change between the years, from 2007, according to the growth of the system usage, through its full implementation, and till 2010.

- Differences between distance learning courses, i.e., pure e-learning courses without any face-to-face contact between tutor and students, provided in the trainee's base office or vessel, in contrast to hybrid or blended courses, which are conducted "on-campus", combining both classic teaching and e-learning support

- Differences between populations, which comprehends seniority and roles. The population is divided in levels or classes, as shown in Figure 2, according to the department to which the trainee belongs. The courses accessible by the "Bareket" system in the "on campus" environment can be divided by the level of the course. There are four levels of courses, where level 1 is the lowest level, and level 4 is the highest. The $4^{\text {th }}$ level is usually manned by officers. The distance learning courses population is divided in three different classes:

○ "Class 1" - these are trainees who are located in offices, with computer infrastructures.

- "Class 2" - these trainees are not located in offices, and have little access to computer infrastructure.

○ "Class 3" - these trainees are not located in offices, but have access to computer infrastructures. 


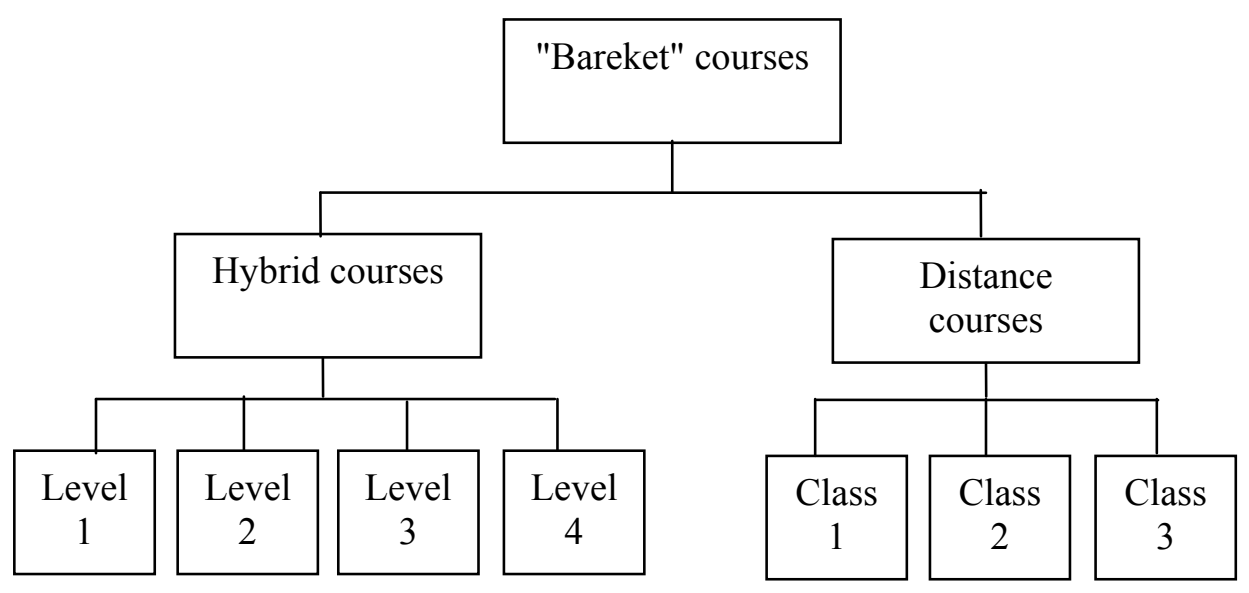

Figure 2 - Type of courses in the "Bareket" System

The data was not analyzed in resolution of specific courses, and neither by individual trainees, so it is not possible to know if one trainee logged-in lots of times, or lots of trainees logged-in one time each. Moreover, the data accumulated resembles the number of log-ins, irrespective of whether a trainee used the system for ten minutes or three hours.

\section{Results}

According to the analysis of accumulated data, it is evident that the usage of the system grew along the years. Figure 3 shows the combination of growth in number of trainees using the system, number of courses supplied by the system, and number of log-ins. The number of trainees using the system increased both along first implementation and full operation periods. Significant growth in number of trainees is observed for the first implementation while moderated growth is observed for the second period of full operation. Therefore, the examination of the effect of the elearning system to time management will be focused on the 2007-2010 years, where 2010 contains data till the end of the third quarter of the year, when this research was conducted. This fact has led to the decision of refining the data examination for 2009, which was the last year with full data.

The growth in usage of the e-learning system is also reflected by the number of courses supplied by the "Bareket" system. A slow evolution can be seen in the first two years, where the infrastructure was built, and a consistent growth in the following years.

Although the number of trainees did not change on a major scale during the 2007-2010 years, the number of log-ins to the system continued to increase over the years. 

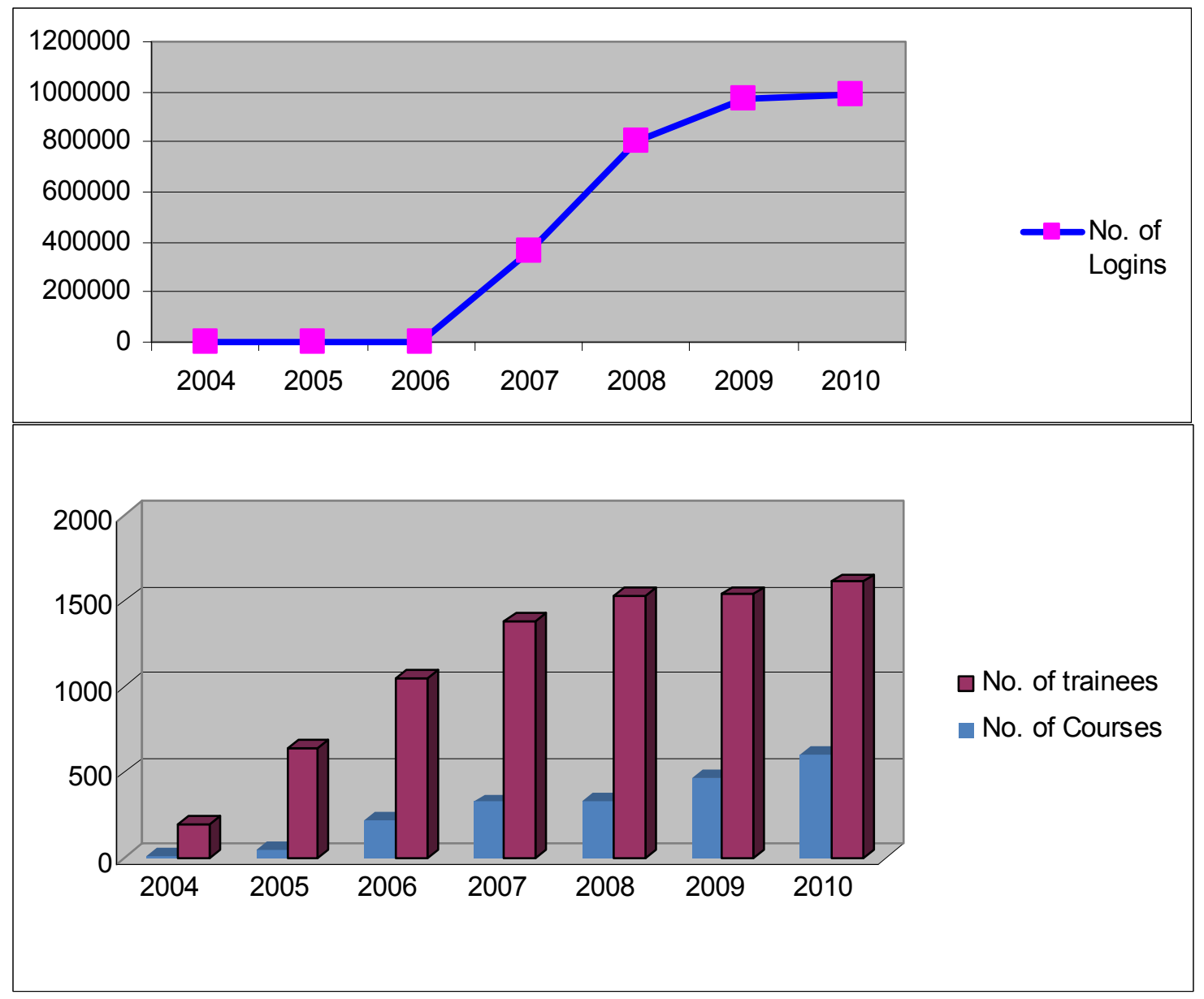

Figure 3 - Number of Trainees, Courses and Log-ins in the "Bareket" System

The figure shows that between 2007 and 2008, the number of trainees grew by $10 \%$, the number of courses by $2 \%$, while the number of log-ins by $120 \%$. Between 2008 and 2009 the number of trainees grew by $1 \%$, the number of courses by $38 \%$, while the number of log-ins by $21 \%$.

The log-ins to the "Bareket" system can be examined by the diurnal time patterns. Figure 4 shows the log-in time to the "Bareket" system, in other words, the number of log-ins according to the 24 hours per day, for each of the years 2007-2010. It is obvious that, according to the growth of trainees over the years, the number of log-ins increases. Furthermore, as it can be seen, the use of the system expands also to the "after work" hours, 18:00 - 24:00.

This data needs more examination, so it further researched, according to two different parameters:

(1) The mode in which the course was supplied, i.e., distance or hybrid learning

(2) The course level or class, as described earlier 


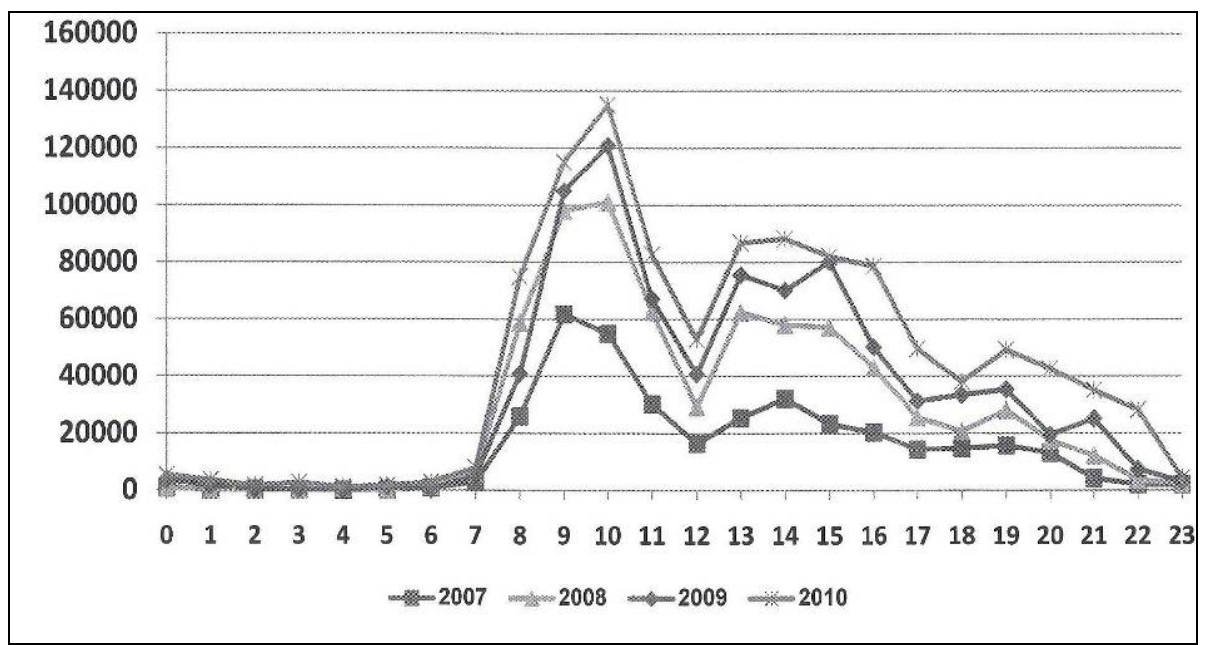

Figure 4 - Log-in Time to the "Bareket" System

Table 1 shows the data according to the mode of learning, distance learning courses and hybrid learning courses.

Table 1: Courses and trainees in distance and hybrid learning

\begin{tabular}{|c|c|c|}
\hline & Distance learning & Hybrid learning \\
\hline Number of courses & & \\
\hline 2007 & 24 & 304 \\
\hline 2008 & 25 & 309 \\
\hline 2009 & 42 & 424 \\
\hline 2010 & 65 & 537 \\
\hline Number of trainees & & 1167 \\
\hline 2007 & 211 & 1281 \\
\hline 2008 & 245 & 1286 \\
\hline 2009 & 251 & 1336 \\
\hline 2010 & 274 & \\
\hline
\end{tabular}

Figure 5 shows the number of log-ins throughout the day (24 hours presentation), in the 20072010 years, in the pure distance learning courses and the hybrid courses. It can be seen that the curves of the distance learning courses are relatively more flat and homogenous during the day, while the hybrid courses, where trainees are fully committed to the course, are more influenced by time. Figure 6 enlarges the graph for the year 2009. In all graphs there is a decrease of log-ins during lunch (12:00-13:00) and a smaller decrease at dinner (around 17:00-18:00). 


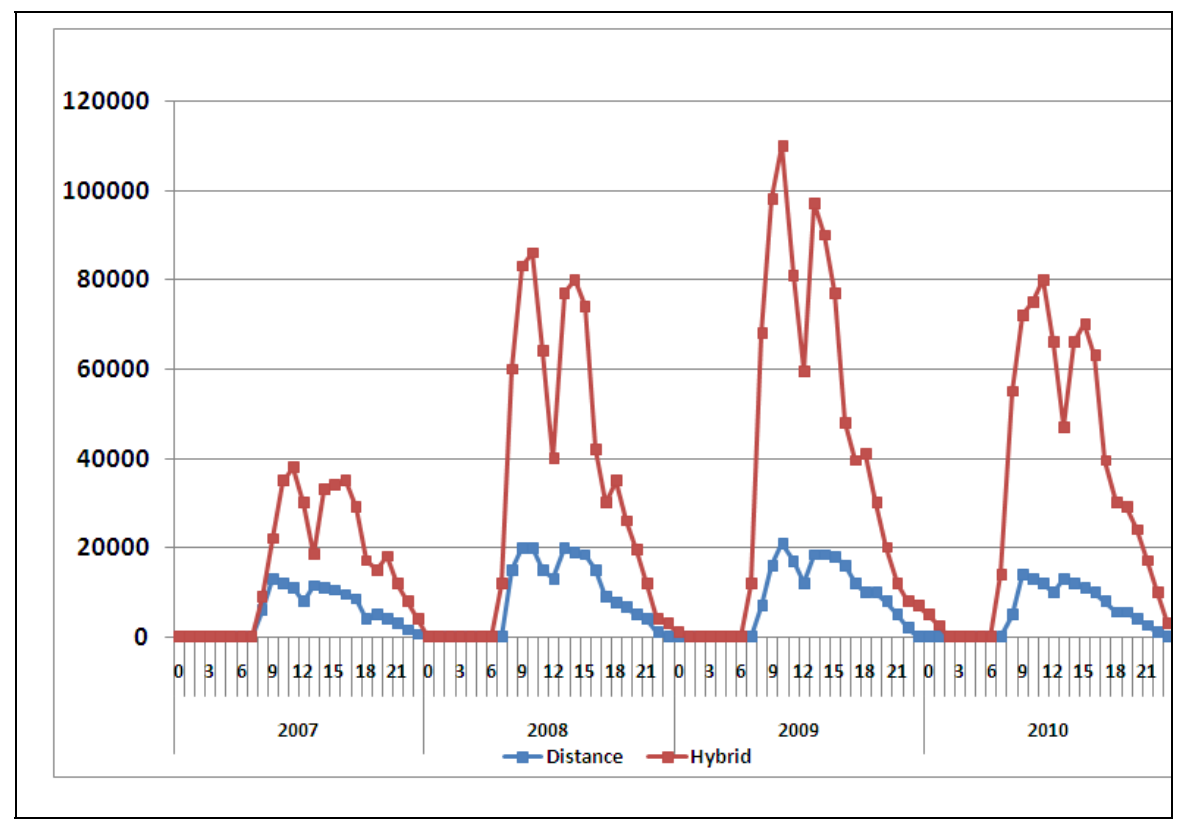

Figure 5 - Log-ins of distance vs. hybrid courses

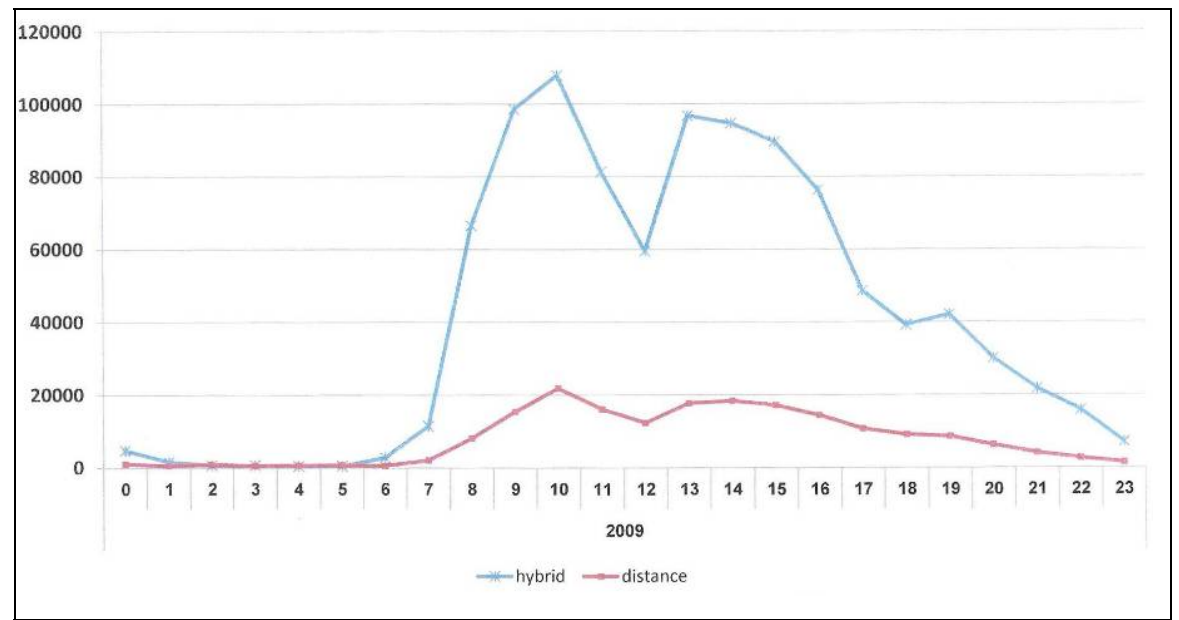

Figure 6 - Log-ins of distance vs. hybrid courses in 2009

Another parameter affecting the time patterns is the difference of the trainees' population, according to the course level or class. Figure 7 shows the growth of log-ins of distance learning in the various classes: "Class 1" courses, where trainees are located in offices, with computer infrastructures; "Class 2" courses where trainees have little access to computer infrastructure and "Class 3" courses, where trainees are not located in offices, but have access to computer infrastructures. In all figures it can be seen that the quantity of log-ins grows during the years, but, in addition, the time pattern changes over the years. More "after hours" are utilized to the learning activities, especially in "Class 1" courses. 


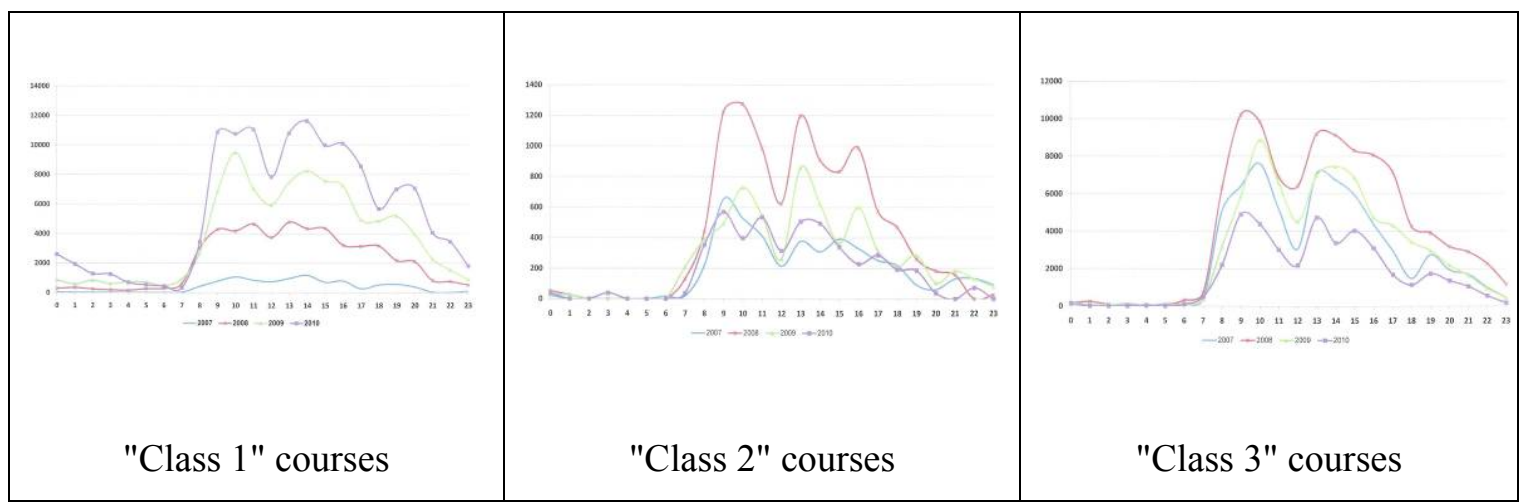

Figure 7 - Log-ins of distance learning - according to classes

Figure 8 shows the growth of log-ins of hybrid learning trainees for first and third level courses. In these kinds of courses, the quantity of log-ins also grows during the years, but the time pattern is more stable. Moreover, there is no much difference in the time management between the various levels. Figure 9 shows the different time patterns according to the four course levels in 2009.

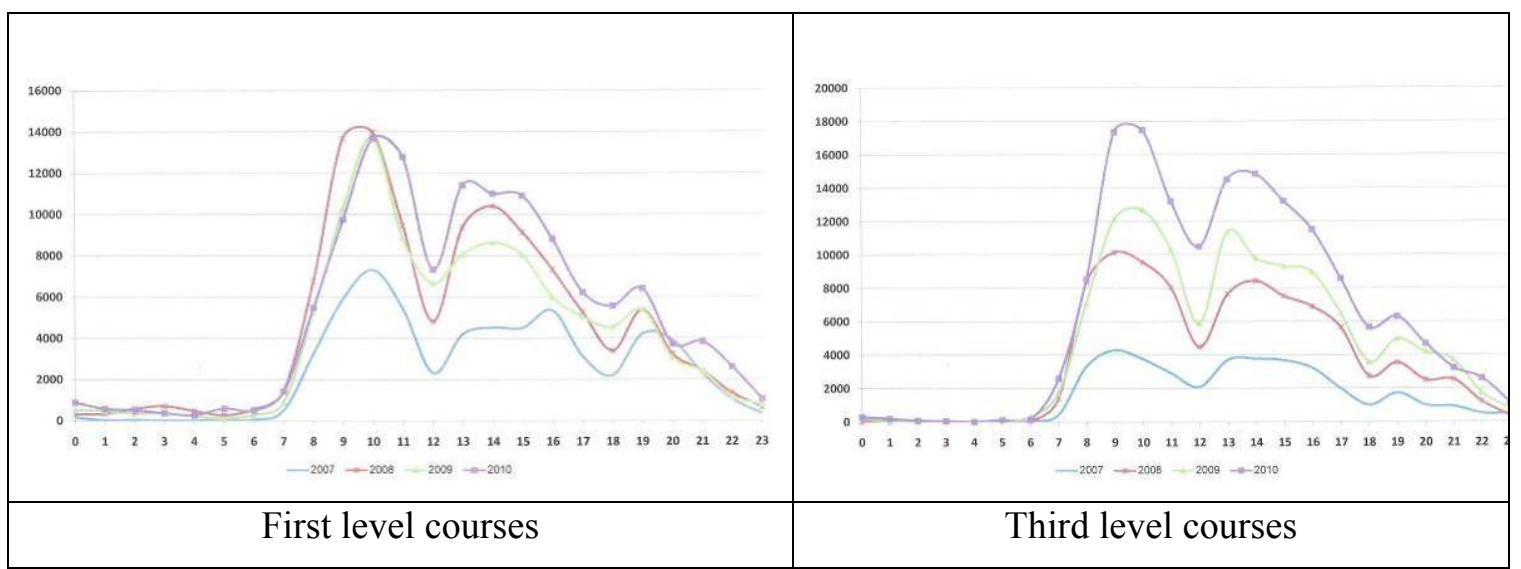

Figure 8 - Log-ins of hybrid learning - according to course level

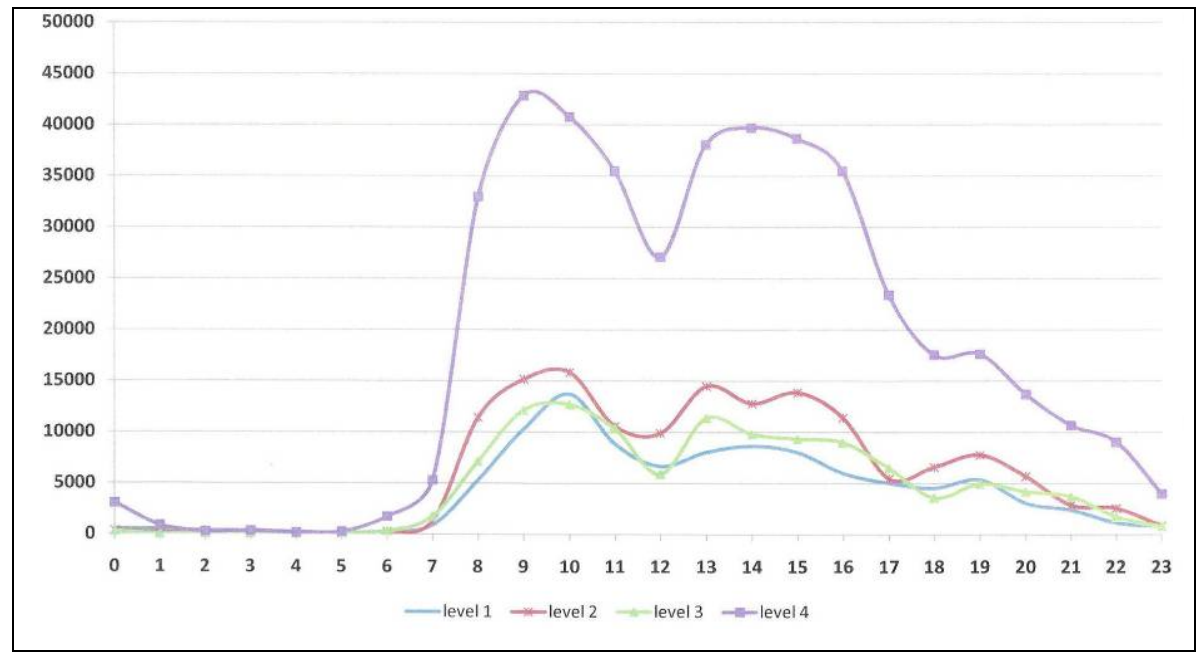

Figure 9 - Log-ins of hybrid learning in 2009, according to course levels 
For each lesson or course, the trainees have to fill in an evaluation form. This is not a learning activity, but is also conducted via the "Bareket" system. As can be seen in Figure 10, this activity is accomplished in the 8:00-18:00 working hours.

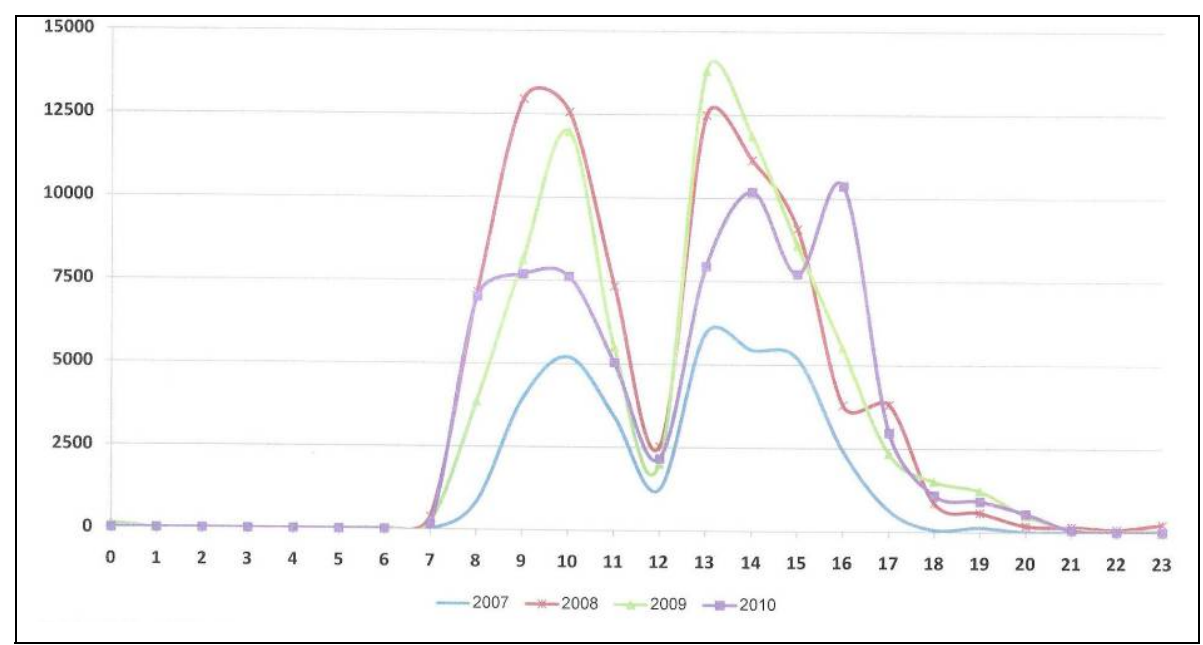

Figure 10 - Log-ins for evaluation forms fill-in

Table 2 summarizes the percent of logins during working hours (8:00-18:00) and after working hours, along the years, according to the mode of learning, i.e., distance learning courses and hybrid learning courses. The percent of logins in the after working hours is constantly increasing in the distance learning courses, while it is stable in the hybrid courses.

Table 2: Log-ins in working and after working hours in distance and hybrid learning (\%)

\begin{tabular}{|l|c|c|c|c|}
\hline & $\mathbf{2 0 0 7}$ & $\mathbf{2 0 0 8}$ & $\mathbf{2 0 0 9}$ & $\mathbf{2 0 1 0}$ \\
\hline Distance learning & & & & \\
\hline Working hours (8:00-18:00) & 86.6 & 84.9 & 82.6 & 78.7 \\
\hline After working hours & 13.4 & 15.1 & 17.4 & 21.3 \\
\hline Hybrid learning & & & & \\
\hline Working hours (8:00-18:00) & 83.1 & 84.3 & 84.7 & 84.2 \\
\hline After working hours & 16.9 & 15.7 & 15.3 & 15.8 \\
\hline
\end{tabular}

As expected, base on the usage pattern throughout the day, the correlation between system usage and time of the day at which the usage take place is fairly weak. It ranges between 0.12 for distance learning at level 2 and 0.39 for hybrid learning at level 2 .

Moreover, the correlation between system usage and the periods of the day (i.e. working and non working hours) is very strong and ranges between 0.89 and 0.99 for distance learning and hybrid learning, respectively (Table 3 ). 
The system usage is greater along the years at both working and non working hours. In addition, it is shown that the correlation between system usage and the type of learning (i.e. hybrid and distance learning) is very strong and ranges between 0.95 and 0.97 for learning at working hours and learning at non working hours, respectively. The system usage is greater along the years for both hybrid and distance learning.

Additionally, the correlation between the number of logins to the system and the passing years is high (0.60). It means that the number of logins to the system is greater along the years. In contrast, the correlation between the number of logins to the system and months is very low $(-0.08)$. It means that there is no linkage between the number of logins to the system and the month in a year in which the system is being used.

Table 3: Statistical Correlations

\begin{tabular}{|l|l|l|}
\hline & Hybrid learning system usage & Distance learning system usage \\
\hline Period of the day & 0.99 & 0.89 \\
\hline & Working hours system usage & Non working hours system usage \\
\hline Type of learning & 0.95 & 0.97 \\
\hline & Years & Months \\
\hline Number of logins & 0.60 & -0.08 \\
\hline
\end{tabular}

\section{Discussion}

During the analyzed period, the system was widely expanded. The number of courses offered in the e-learning environment was augmented by around 150 per year (circa 400 in 2008, 550 in 2009 and 700 in 2010). The number of trainees grew while the "Bareket" system was under construction, but has been stabilized when the system reached its entire objectives. Albeit the number of trainees did not change during the 2008-2010 years, the number of log-ins to the system continued to increase over the years, apparently as a consequence of the growth in courses.

The number of log-ins reflects the usage of the e-learning system, which obviously grows when more courses are taught through the system. This growth can be clearly seen in over the years, in all kind of classes, levels and modes of learning. In addition to the leverage of the graphs, which are explained by this growth, the results show that the learning hours expand thru the evening hours, changing the learning time management patterns.

Humanity has organized its day-to day activities base on the diurnal patterns of sleep, work and play (Klepeis et al., 2001). It is important to emphasize that the log-in time resembles the starting learning time. The trainee, who logs-in to the "Bareket" system at 23:30, can still be using the system three hours later. The results show that the general time pattern includes hours with almost no log-ins (0:00 - 6:00) which are obviously the sleeping hours, a steep rise from 6:00 till 9:00 which is the peak of log-ins, a decrease towards 12:00, where lunch is served; then the log-ins raise again, but with a lower peak, decreasing towards the dinner hour, about 17:00-18:00 and then a slowly decrease, till 24:00. This pattern divides the day in some parts: 0:00-6:00 - sleeping hours, 7:00- 12:00 learning hours, 12:00-13:00 lunch, 13:00-17:00 learning hours, 17:00-18:00 dinner, and the most interesting part is the extending learning hours from 18:00 till 24:00.

E-learning systems may change the operational pattern of activities throughout the day. The usage of an e-learning system, which is asynchronous and independently used by the trainees, broadens the learning hours from standard working hours, and spread all over the day. Trainees are taking 
advantage of increased time flexibility. As shown in the results, the use of the "Bareket" system causes the enlargement of the learning hours along the day. The use of the system at these hours is constantly increasing. Moreover, it can be seen that although the total use of the system in the morning hours, 8:00-12:00 is growing, the work in these hours is more concentrated, apparently because in the morning hours there are more duties to be done, and less time remains for learning activities. The trainees are no more restricted by the confined working hours, but can use the system also after the regular hours. This tendency is enlarged along the years. Moreover, it can be seen that different kinds of population behaves in diverse ways.

As explained, the "Bareket" system is used in two different modes: (1) Distance learning - where the trainees learn at their own pace, without leaving their base or vessel, and combine work with study, at their convenient hours. (2) Hybrid learning -"on campus", combining e-learning with frontal lectures or practical training. In this case the trainees leave their bases and vessels and are gathered for a course defined time. In each mode, the "Bareket" system is available to the trainees all over the day.

The general diurnal time pattern exists in both learning modes, as seen in Figure 6, but they behave in a different way. In the distance learning courses, the time pattern is more uniform during the day, because trainees interlace working and learning, while in the hybrid mode, where trainees are focused only in the learning activities, the pattern changes during the day hours. The percent of log-ins in the "after-work" hours is increasing along the years in the distance learning courses.

The distance learning is composed of three different populations, with characteristics which affect the behavior and time pattern adoption. For example, the "Class 1" populations, where trainees work and study from their offices with computer infrastructure, and "Class 3" population, where trainees are not located in offices, but have access to computer infrastructures, exploit the evening and night hours. In "Class 2" population, trainees have little access to computer infrastructure and therefore the usage is scant and more homogenous through the day.

In the hybrid learning courses, the learning hours are also enlarged, but there is no significant disparity between the level of the courses and trainees. This can be explained by the fact that hybrid courses are conducted in a training base, "on-campus", away from the working base, and the whole day is dedicated for training.

In various studies conducted to understand the influences of the full day availability of computers and communications infrastructure to the time usage of these resources, the researches reported that the usage is almost totally in the working hours. Spennemann (2007) examined server traffic statistics in Australian universities and showed that students accessed the online resources mostly during the office hours, meaning 72\% between 08:00-17:00, and during the work-days. Lukaitis and Davey (2010) examined three types of courses at RMIT university in Australia and found 58\%-76\% between 09:00-17:00, regardless of being the courses fully online or hybrid and although a significant proportion of students studied part time and worked full time. Burr and Spennemann (2004) showed similar usage patterns in online forums. Petrova and Sinclair (2005) observed that students prefer to log-in between 10:00 to 18:00. In another study, Spennemann et al. (2007) examined the student utilization of computer infrastructure available 24/7. They found that the usage rise steeply between 7:00 and 9:00, and drops between 14:00 and 18:00, which show a strongly diurnal pattern, and almost no usage in the evenings. Likewise, as shown in the results, the mass of the trainees in this research, logged in during the day, which is broader than in the cited research, 08:00-18:00, showing a diurnal pattern. Even so, the "diurnal" hours were spread to a larger part of the day, compared to the other researches. All those studies have been performed on population of students, who study in a less restricted environment than the Navy. One of the reasons that universities use online learning is to be more flexible to students who 
miss classes, or are less engaged in campus life (Lukaitis and Davey, 2010). This is not the case in the Navy, and even less in the hybrid mode which is performed "on-campus", because the trainees are in a restricted framework, and cannot miss classes according to their wills.

Other activities performed using the e-learning infrastructure, but not directly affecting the trainees' knowledge, are mostly accomplished during the 8:00-18:00 working hours, for example, filling-in evaluation forms.

All graphs show an acute decrease of utilization during the lunch (12:00-13:00) and a moderated reduction of log-ins during dinner (17:00-18:00). The reason is that soldiers do not have the possibility to dine at different hours and they have to go to the dinning room when it is open. Nevertheless, it looks as some trainees decide to skip the meals.

The electronic learning may not be efficient if the trainee does not find the time to study with the system. This is a problem in organizations, where the trainees are not forced to spend some of their time in learning activities (Govindasamy, 2002, Lee, 2006). This is not the case in the "Bareket" e-learning system in the Israeli Navy, where the trainees are soldiers that are obliged to perform the learning activities. Despite that, the usage of the system in the hybrid courses proceed a constant augmentation $(35,000,80,000,100,000$ and 120,000 in the peak hour, for 2004-2010, respectively) while in the distance learning the growth is very moderated (around 20,000 in the peak hour). This results fit with the work of Petrova and Sinclair (2005) who found that the most extensive use of online learning is for enhancement of face-to-face classes, with $48 \%$ courses using online learning in that way. Still, it can be seen that distance learning for trainees who are not in an office environment and do not have available infrastructure (distance learning, "Class 2") make a minimal use of the e-learning system. This correlates with Beasley and Smyth (2004) research, who found that students do not always use the online learning environment in all the ways that might have been intended, or indeed in the most effective ways. In this case it is more efficient to organize an "on-campus" course when training is needed. The distance learning moderated usage can also be explained from the attention economy perspective (Davenport \& Beck, $2000,2001)$. These trainees are usually very busy and have to finish their duties and do not have time for learning activities, so they adopt a satisficing approach (Simon, 1957, 1971), and complete only the minimum needed.

\section{Future Research}

Future research needs to check the difference in time patterns according to course attributes, like length of courses, short courses (1-2 weeks) may behave different than long courses with some month duration. Another examination can be held during the life-time of the courses, whether the time pattern changes before exams, at the beginning or end of the course, etc. An additional interesting research can be done on the duration of the sessions, in other word, for how long the trainees use the e-learning system each time they log-in, in the different hours of the day.

The data accumulated will be also examined according to a second perspective of time management, which is the day of week pattern. Human behavior in western cultural environments follows a pattern of work days and work free weekends (Klepeis et al., 2001). The e-learning systems make it feasible to use them all days, also on weekends. However, the courses in the Navy are conducted on week-days, and part of the trainees return on weekends to their home, where there is no possibility to connect to the "Bareket" system.

Another future research will compare the data accumulated by actual usage with a qualitative study including interviews and a survey. In this way, it will be possible to collect the trainees, instructors and the commanders attitude, and analyze this data with the gathered till now. 


\section{Conclusion}

This study examined diurnal time patterns in the usage of the "Bareket" e-learning system implemented in the Israeli Navy. The e-learning system is utilized in two modes: distance learning and "on-campus" hybrid learning. The findings show that trainees take advantage of the increased time flexibility, and enlarge the time spent in the e-learning system, in both modes. Moreover, the diurnal time patterns of the learning in each mode are different and reflect the characteristics of the modes: concentration in learning in the hybrid mode, or combining work and courses in the distance mode. Additionally, the results were refined according to diverse classes or levels in each mode, distinguishing different behaviors, especially in the distance learning, according to the daily accessibility of the trainees to the computer infrastructure. In addition, the findings show that the diurnal time pattern changes over the years expanding the learning time toward the "after work" hours, providing more hours to study. The results of this study can trigger the operators of such systems, to adapt the working hours of the supporting staff to the active hours, for example by working in shifts. Moreover, in the case of trainees in the army, the trainees are used, during their duty, to change the activity hours according to the needs, for example work by night and sleep during the day. Likewise, the different courses can be adapted to their work hours, so groups of trainees will study by night thus the load of the e-learning system can be balanced.

\section{References}

Allen, M., Mabry, E., Mattrey, M., Bourhis, J., Titsworth, S., \& Burrell, N. (2004). Evaluating the effectiveness of distance learning: A comparison using meta-analysis. Journal of Communication, 54(3), 402-420.

Beasley, N., \& Smyth, K. (2004). Expected and actual student use of an online learning environment: A critical analysis. Electronic Journal on e-Learning, 2(1), 43-50.

Bonk, C. J., \& Wisher, R. A. (2000). Applying collaborative and e-learning tools to military distance learning: A research framework. Alexandria, VA: U.S. Army Research Institute for the Behavioral and Social sciences. Retrieved from http://www.publicationshare.com/docs/Dist.Learn(Wisher).pdf

Burr, L., \& Spennemann, D. H. R. (2004). Patterns of user behaviour in university online forums. International Journal of Instructional Technology and Distance Learning, 1(10), 11-28.

Capper, J. (2003). E-learning: Current status and international experience. Washington, D.C: Word Bank. Retrieved November 1, 2010 from http://empresas.sence.cl/documentos/elearning/Elearning.\%20Art $\% \mathrm{C} 3 \% \mathrm{ADculo} \% 20 \mathrm{de} \% 20 \mathrm{Joanne} \% 20 \mathrm{Capper} \% 20($ Ingl $\% \mathrm{C} 3 \% \mathrm{~A} 9 \mathrm{~s})$.pdf

Cukušić, M., Alfirević, N., Granić, A., \& Garača, E. (2010). E-learning process management and the elearning performance: Results of a European empirical study. Computer and Education, 55(2), 554565 .

Davenport, T. H., \& Beck, J. C. (2000). Getting the attention you need. Harvard Business Review, 78(5), 118-126.

Davenport, T. H., \& Beck, J. C. (2001). The attention economy: Understanding the new currency of business. Boston, MA: Harvard Business School Press.

Elgort, I. (2005). E-learning adoption: Bridging the chasm. Proceedings of ASCILITE'2005, Brisbane, Australia, vol.1, p. 181-185. Retrieved from http://www.ascilite.org.au/conferences/brisbane05/blogs/proceedings/20_Elgort.pdf

Emami, H., Aqdasi, M., \& Asousheh, A. (2008). Key success factors in e-learning in medical education. Journal of Medicine Education, $12(3,4), 81-89$. Retrieved February 19, 2011 from http://asianvu.com/digital-library/elearning/e-learnng_in_medical_education.pdf

Foltynek, T., \& Motycka. A. (2009). Time management in e-learning. In Research, reflections and innovations in integrating ICT in education [Proceedings Book of the m-ICTE2009 Conference], Badajoz, 
Spain (pp. 250-254). Retrieved November 1, 2010 from

http://www.formatex.org/micte2009/book/250-254.pdf

Govindasamy, T. (2002) Successful implementation of e-learning: Pedagogical considerations. Internet and Higher Education, 4(3-4), 287-299.

Hogarth, K., \& Dawson, D. (2008). Implementing e-learning in organisations: What e-learning research can learn from instructional technology (IT) and organisational studies (OS) innovation studies. International Journal on E-Learning, 7(1), 87-105.

Juhary, J. B. (2005). Malaysian defence and e-learning. US-China Education Review, 2(9), 35-41.

Kathawala, Y., \& Wilgen, A. (2004) E-learning: Evaluation from an organization's perspective. Training and Management Development Methods, 18(4), 501-506.

Klepeis, N. E., Nelson, W. C., Ott, W. R., Robinson, J. P., Tsang, A. M., Switzer, P., et al. (2001). The National Human Activity Pattern Survey (NHAPS). A resource for assessing exposure to environmental pollutants. Journal of Exposure Analysis and Environmental Epidemiology, 11(3), 231-252

Lee, Y. (2006) An empirical investigation into factors influencing the adoption of an e-learning system. Online Information Review, 30(5), 517-541.

Lukaitis, A., \& Davey, B. (2010). Motivations of the online student. The Journal of Issues in Informing Science and Information Technology, 7, 25-39. Retrieved from http://iisit.org/Vol7/IISITv7p025039Lukaitis782.pdf

Marengo, A., \& Marengo, V. (2005). Measuring the economic benefits of e-learning: A proposal for a new index for academic environments. Journal of Information Technology Education, 4, 329-346. Retrieved from http://www.jite.org/documents/Vol4/v4p329-346Marengo51.pdf

McVeigh, H. (2009). Factors influencing the utilisation of e-learning in post-registration nursing students. Nurse Education Today, 29(1), 91-99.

McPherson, M., \& Nunes, M. B. (2006). Organizational issues for elearning: Critical success factors as identified by HE practitioners. The International Journal of Educational Management, 20(7), 542-558.

Naveh, G., Tubin, D., \& Pliskin, N. (2004). Critical success factors of e-learning implementation at a university. Proceedings of the First European Conference on E-Learning and Management Education, Milan, Italy. Retrieved from http://www.cis.gsu.edu/ emonod/education/

Newton, D., \& Ellis, A. (2005). Effective implementation of e-learning: A case study of the Australian army. Journal of Workplace Learning, 17(5/6), 385-397.

Petrova, K., \& Sinclair, R. (2005). Business undergraduates learning online: A one semester snapshot. International Journal of Education and Development Using Information and Communication Technology, 1(4), 69-88.

Quentin-Baxter, M., Kelly, J., Probert, S., MacMahon, C., \& Merrell, G. (2008). A model for evidencing the benefits of technology enhanced learning in higher education in the UK. Proceedings of ASCILITE Melbourne.

Sela, E., \& Sivan, Y. (2009). Enterprise e-learning success factors: An analysis of practitioners' perspective (with a downturn addendum). Interdisciplinary Journal of E-Learning and Learning Objects [Special Series of Selected Best Papers, Fourth Chais Conference on Instructional Technologies Research 2009: Learning in the Technological Era], 5, 359-378. Retrieved from http://www.ijello.org/Volume5/IJELLOv5p335-343Sela674.pdf

Selim, H. M. (2007). Critical success factors for e-learning acceptance: Confirmatory factor models, Computers and Education, 49(2), 396-413.

Simon, H. A. (1957). Models of man: Social and rational. New York: John Wiley and Sons.

Simon, H. A. (1971). Designing organizations for an information-rich world. In M. Greenberger (Ed.), Computers, communications and the public interest (pp.40-41). Baltimore, MD: Johns Hopkins Press. 
Spennemann, D. H. R. (2007). Learning and teaching 24/7: Daily internet usage patterns at nine Australian universities. Campus-Wide Information Systems, 24(1), 27-44.

Spennemann, D. H. R., Atkinson, J., \& Cornforth, D.(2007). Sessional, weekly and diurnal patterns of computer lab usage by students. Computers and Education, 49(3), 726-739.

Stonebraker, P. W., \& Hazeltine, J. E. (2004). Virtual learning effectiveness. The Learning Organization, $11(2 / 3), 209-225$.

Trinidad, S., \& Pearson, J. (2004). Implementing and evaluating e-learning environments. In R. Atkinson, C. McBeath, D. Jonas-Dwyer, \& R. Phillips, (Eds.), Beyond the comfort zone: Proceedings of the 21st ASCILITE Conference (pp. 895-903). Perth, Australia: Australasian Society for Computers in Learning in Tertiary Education

Tung, M. C., Huang, J., Keh, H. C., \& Wai, S. S (2009). Distance learning in advanced military education: Analysis of joint operations course in the Taiwan military. Computers and Education, 53 (3).

Vanijja, V., \& Supattatham, M. (2006). Statistical analysis of elearning usage in an university. The Third International Conference of eLearning for Knowledge-Based Society (IJCIM 2006), Bangkok, Thailand, p. 22.1-22.5.

Vryonides, M. (2008) A sociological inquiry into time management in postgraduate studies by e-learning in Greece. European Journal of E-learning, 6, 67-76.

Wang, Y., Wang, H., \& Shee, D. Y. (2007). Measuring e-learning systems success in an organizational context: Scale development and validation. Computers in Human Behavior, 23(4), 1792-1808.

Wisher, R., \& Sabol, M., (2002). Distance learning: The soldier's perspective. Alexandria, VA: Human Resource Research Organization.

Zhang, D., Zhao, J. L., Zhou, L., \& Nunamaker, J. F., (2004). Can e-learning replace classroom learning? Communications of the ACM, 47(5), 75-79.

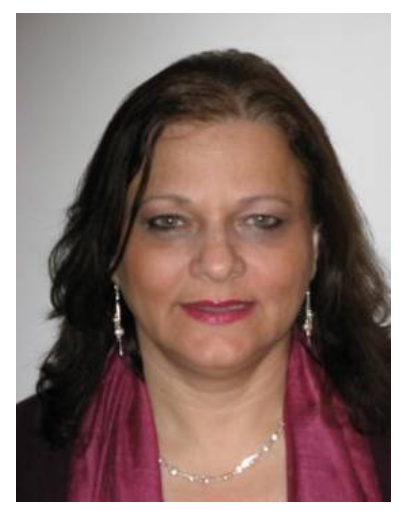

\section{Biographies}

Dr. Ruti Gafni holds a PhD from Bar-Ilan University, Israel in the Business Administration School, focusing in Information Systems. She holds an M.Sc. from Tel Aviv University and a BA (Cum Laude) in Economics and Computer Science from Bar-Ilan. She has more than 30 years of practical experience as project manager and analyst of information systems. She teaches in the Management and Economics MBA program, both at the Open University of Israel and at Netanya Academic College, and in the Information Systems BA program at Tel Aviv-Yaffo Academic College.

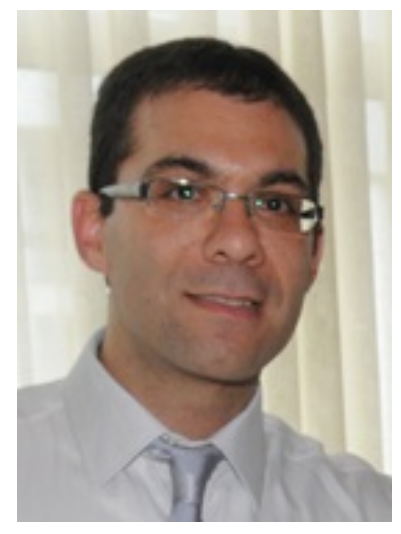

Levi Shaul is a PhD candidate in the Information Systems Department at the University of Bar Ilan. Levi received a BSc (Hons.) in Mechanical Engineering at University of Tel-Aviv and his MA in Business Administration from Technion-Institute of Technology. Levi is a senior product manager at an information system division. 


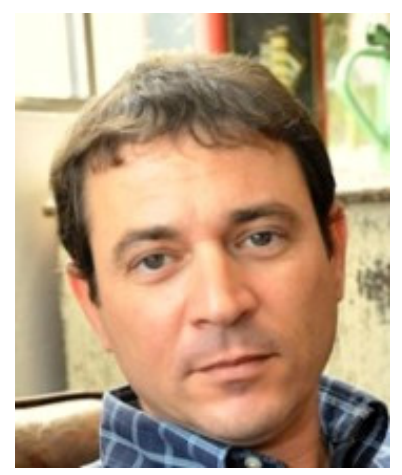

Doron Tauber, $\mathrm{PhD}$, lecturer at Bar-Ilan University and at Netanya Academic College. Doron received his BA in Mathematics \& Computer Science at University of Haifa (Hons.), MA in Business management from Ben-Gurion University, and his PhD from Bar-Ilan University. 